\title{
On the Systemic Features of Urban Systems. A Look at Material Flows and Cultural Dimensions to Address Post-Growth Resilience and Sustainability
}

\author{
Silvio Cristiano ${ }^{1,2,3 *}$, Amalia Zucaro ${ }^{4 *}$, Gengyuan Liu ${ }^{5}$, Sergo Ulgiati ${ }^{3,5}$ and \\ Francesco Gonella ${ }^{1,2}$
}

${ }^{1}$ Research Institute for Complexity, Università Ca' Foscari Venezia, Venice, Italy, ${ }^{2}$ Department of Molecular Science and Nanosystems, Università Ca' Foscari Venezia, Venice, Italy, ${ }^{3}$ Department of Science and Technology, Università degli Studi di Napoli "Parthenope", Naples, Italy, ${ }^{4}$ Division Resource Efficiency, Italian National Agency for New Technologies, Energy, and Sustainable Economic Development (ENEA), Rome, Italy, ${ }^{5}$ School of Environment, Beijing Normal University, Beijing, China

\section{OPEN ACCESS}

Edited by:

Feni Agostinho,

Paulista University, Brazil

Reviewed by:

Daniel Elliott Campbell,

University of Rhode Island,

United States

Hongfang Lu,

South China Botanical Garden (CAS),

China

*Correspondence:

Silvio Cristiano

silvio.cristiano@unive.it;

silvio.cristiano@uniparthenope.it Amalia Zucaro

amalia.zucaro@enea.it

Specialty section:

This article was submitted to

Urban Resource Management,

a section of the journal

Frontiers in Sustainable Cities

Received: 02 December 2019

Accepted: 30 March 2020

Published: 22 May 2020

Citation:

Cristiano S, Zucaro A, Liu G, Ulgiati S and Gonella F (2020) On the Systemic

Features of Urban Systems. A Look at Material Flows and Cultural Dimensions to Address Post-Growth Resilience and Sustainability. Front. Sustain. Cities 2:12. doi: 10.3389/frsc.2020.00012
Urbanization is widely recognized as a relentless trend at the global level. Nevertheless, a comprehensive assessment of urban systems able to address the future growth and decline of cities is still lacking. Urban systems today rely on abundant resources, flowing in from other regions, and their future availability and accessibility should be taken into consideration to ensure urban well-being and resilience in likely post-growth scenarios. A logical framework to address the challenge of urban planning and management to promote long-term urban system sustainability is proposed. Systems thinking and diagramming are applied, while comprehensively tracking the key material flows upon which cities depend back to their sources. First, the nexus among resources and urban activities is identified, and then its circularity is framed within a wider discourse on urban sustainability and resilience. Discussion is carried out within a two-fold perspective of both existing and newly built environments, while related economies are analyzed in order to find possible game-changing scenarios.

\footnotetext{
Keywords: material and immaterial drivers, post-growth, resilience and sustainability, urban metabolism, systems thinking, urban ecology, sustainable planning and design, cities
}

\section{INTRODUCTION}

Urbanization is widely recognized as a relentless trend at the global level, with $55 \%$ of the world's population already living in urban areas. Projections show that the urban population will increase up to 68\% by 2050 (United Nations Department of Economic Social Affairs, 2018), on an ever-growing denominator, which is expected to approach 10 billion by this time (United Nations Department of Economic Social Affairs, 2019). Despite such significant numbers, a comprehensive assessment of urban sustainability able to envision the cities into the rest of this challenging century is still lacking. Projections on the demand for urban growth may not be the correct point to address, because it is the socio-ecological supply that might not be able to keep up with this pace. In fact, today, urban systems rely on abundant resources, goods, and technologies flowing in from other regions, thanks to a combination of economic, geopolitical, and sometimes military conditions. Therefore, the future availability and accessibility of such 
resources, goods, and technologies must be taken into consideration to verify that existing and future conditions are likely to allow for such urban expansion (hence resource use), ${ }^{1}$ together with related urban well-being and resilience in likely post-growth scenarios. By 2050, two thirds of the global population might suffer from land and water scarcity, as well as food insecurity (Rivas and Nonhebel, 2016), with land use closely connected to the ever-growing urbanization. In addition to the non-renewable sources, such as fossil fuels, other crucial raw materials essential to global economies are also expected to diminish, thus constraining the planet within its physical limits (as first pointed out by Meadows et al., 1972; clearly explained in Calvo et al., 2017, and graphically illustrated in Cristiano, 2019). Furthermore, social limits must be also taken into account (Hirsch, 2005), including the progressive displacement of exploited cheap labor (see Demaria et al., 2013; D’Alisa et al., 2014; Cristiano, 2018). Urbanization, economic growth, and resource consumption (above all, energy) are all intertwined with one another, as recently analyzed, for example, by Zhao and Wang (2015) with a focus on Chinese trends. Since urbanization, economic growth, and resource consumption have been projected as ever increasing in the next decades, some underlying issues should be explored in light of what we have reported so far. First, physical and social limits exist, and current sustaining flows of energy, materials, goods, and labor cannot be taken for granted forever. Second, global urbanization has little to do with the current narrative of smart and sustainable cities and buildings (Albino et al., 2015; Gonella et al., 2019; Joss et al., 2019) and often implies unsafe and unhealthy slums and shelters for desperate job seekers. As a result, the assumed benefits of cities are not equally distributed, and many people have started to call for a "right to metabolism" (Olsen et al., 2018), that is, more equal access to both the sustainable and unsustainable driving flows of megalopoleis. Third, the effects of such economic urbanization patterns have already reached critical levels in terms of pollution and climate change. Moreover, because of their location and economic subalternity (Barca, 2012a,b; Cristiano, 2018), not all countries and populations undergo the same environmental and climate risks (Brulle and Pellow, 2006; Martinez-Alier et al., 2016; Anand, 2017; Pulido and De Lara, 2018). All that said, it is enough to acknowledge that current global strategies to attain sustainability (Sachs, 2012; Griggs et al., 2013; United Nations, 2015) are far from reaching their objectives, and several of the Sustainable Development Goals seem threatened, in particular, no poverty (\#1), good health and well-being (\#3), clean water and sanitation (\#6), affordable and clean energy (\#7), reduced inequalities (\#10), climate action (\#13), and peace, justice, and strong institutions (\#16). Virtuous planning paths for sustainable cities and urban metabolism are therefore urgently required. However, this cannot be limited to technical and sectorial approaches and proposals, but rather needs comprehensive and transdisciplinary approaches-including consideration of the cultural and political dimensions-while offering recursive dialogue and double-checks to ensure good levels of action. From

\footnotetext{
${ }^{1}$ For a critique of the expansion paradigm and resource use, see Cristiano and Gonella (2019).
}

this perspective, there is a clear need for a better understanding of urban energy and material flows, as well as how they can point to ecological sustainability and socially distributed well-being in cities. This calls for guiding urban sustainability assessment with clear, integrative sustainability principles. Therefore, this work aims to address the complexity of urban sustainability, starting from the identification of the main drivers and systemically placing potentials and limits on the implementation of circular patterns as systematic alternatives, requiring a fundamental change in our way of thinking. The use of systems thinking and emergy concepts is suggested, within a holistic perspective, as comprehensive transdisciplinary approaches to explore the dynamics of the evolution of the city.

\section{MATERIALS AND METHODS}

\section{Systems Thinking}

The city is a complex system, and its complexity lies mostly in the intertwined network of feedback relations among its elements, be they physical (infrastructure), political, economic, or environmental. Any attempt to characterize the city's complexity must take into account how the feedback network acts as a driver of self-organization, following patterns of operation that are intrinsically systemic, and thus may exhibit counterintuitive or non-linear behaviors difficult to predict. Technological and strategic innovation framed in terms of "business as usual" is still seen as sufficient to guarantee the resilience and sustainability of the cities, despite the real possibility of socioeconomic collapse that climate change research is addressing (Ripple et al., 2019; United Nations, 2019). In fact, most of the literature concerning the systemic analysis of cities (e.g., Huang et al., 2006; Araos et al., 2016, among others) reports on systemic approaches aimed at pointing out a collection of indicators of system condition. The selection of indicators for urban sustainability assessment is not often guided by a theoretical framework, because the literature framing sustainability assessment has often targeted the national and global scales (Cohen, 2017). The water-energy nexus in urban systems, considering the consumption patterns of water and energy in buildings, residential sectors, and production sectors, can provide important insights for sustainable city planning (Fan et al., 2019). Linking urban metabolism to policy strategies is necessary in order to measure and change urban sustainability performances, by developing the interdisciplinary practice of urban metabolism assessment. Therefore, it is fundamental to discuss and to more deeply understand the complexity of future urban development and management, going much beyond the linear and monodimensional approach of just measuring a city's population, energy consumption, or gross domestic product (Ulgiati and Zucaro, 2019). This addresses sustainability issues based on multiple trade-offs but disregards the complex non-linear character of urban systems, emerging from the network of feedbacks of urban elements (Jackson, 2000; Meadows, 2008; Sterman, 2012). Therefore, an analytical representation of the configurational features of the urban elements is therefore necessary for the definition of any policy action aimed at attaining the integrated sustainability of the city (Luna-Reyes and Andersen, 2003). A suitable general systemic approach is grounded in systems thinking 
(Forrester, 1961; Odum, 1983), in particular, in the stock-flow (SF) representations of systems (Sterman, 1994, 2012; Meadows, 2008). Systems thinking originated as a development of the pioneering work by Ludwig von Bertalanffy (1968), finding application in several fields dealing with the study of complex systems, especially environmental and socioeconomic ones (as recently reviewed by Monat and Gannon, 2015). "Systems thinking" is usually considered one of the systemic approaches included in the general definition of "systems science," which collects methods aimed at studying a system through its collective behavioral features. From an epistemological point of view, systems thinking addresses concise descriptions that use a low number of state variables and real flows of matter, energy, or information. A comprehensive and updated review of all the definitions and aspects related to the systems thinking, together with the history of its development, may be found in Monat and Gannon (2015). Representations based on the use of the "stocks and flows" concept have been developed separately in various disciplines. For example, economists used to call them "levels" and "rates," respectively. Back in 1961, Forrester (1961) introduced SF description dealing with management issues, but similar concepts may be found in physics, in particular thermodynamics, where system states are often expressed by a set of time-dependent extensive variables. The evolution of the system state is then determined by differential equations that point out the mathematical relationship existing between the change of a stock and the flows generated by that. Generally speaking, SF diagrams allow a shift of the attention from the events and their direct causes to the systems that are responsible for their occurrence, in turn resulting from the configuration of feedback structures. By identifying the observable dynamical patterns of the system on simulation, it is possible to describe its operational features and to find the possible leverage points for managing its sustainability in an integrated way. The SF approach starts by identifying a limited number of extensive variables (stocks), those necessary to describe the flows of resources actually occurring in the system. Stocks can be seen as state variables of the system, whose dynamics are determined by the feedback network connecting one to another, as well as by the effects of external factors affecting system inflows and outflows.

Since the variables that define the metabolism of a city may vary simultaneously and "in subtly interconnected ways" (Orr, 2014), a systemic approach is not sufficient per se to address the city's complexity, unless it explores the dynamics of the evolution of the city. This is one of the main points of this work: if an integrated systemic description of urban metabolism is necessary, it must also be able to address the dynamics of the city, which is expected to self-organize in a complex way depending on the changes in a set of external driving forces. This aspect of the systemic approach is rarely addressed by most studies on urban systems, which most of all aim at providing a set of indicators suitable for short-term decision-making processes.

An SF diagram contains the relevant stocks along with the relevant flows and processes that define system operations. Stocks are elements containing a quantity of something (moles of atoms, energy, information, people, money, and so on) and are diagrammed as shield-like elements. They are changed over time by the action of flows, thus acting as delays or buffers in the system. Flows-represented by arrows-are physical flows of resources of different forms and units. Under the framework of Energy Systems Theory (Odum, 1983), which is a particular systemic approach, and using the Emergy methodology (Odum, 1996), it is possible to represent stocks and flows in the same unit of emergy, the solar emjoule (sej), which accounts for all the available energy directly and indirectly used per unit of time, area, and etc., and so allows the quantification of the description of the complex system. Although the details of emergy accounting are well beyond the scope of this article, it is worth noting how it provides a mathematical model and evolutionary justification of how and why systems develop autocatalytic modules based on reinforcing feedback loops (Odum, 1994; Campbell, 2001), a behavior that in ecosystems is at the basis of various adaptation mechanisms.

Being that a city is an open system, a correct description of its behavioral patterns should connect the resource flows to the supporting natural and socioeconomic environment, which in turn is expected to develop autocatalytic behaviors in the supporting action (Odum, 1988). The intrinsic systemic character of the problems of a city comes from undesirable features of the system structures that produce them, so that the city should be regarded as the source of many of its own problems. Tracing cause-effect paths by separating small, easy-to-describe subsets is certainly a good means to describe some aspects of the urban metabolism, but the overall sustainability of a city requires a holistic-systemic perspective. Indeed, systemic thinking relies on physical principles, such as the second law of thermodynamics, or Lotka's power maximization principle (Lotka, 1922), in recent years extended to include the quality of energy using the emergy concept (Hall, 2004). In the words of Odum (1996), "[i]n the competition among self-organizing processes, network designs that maximize empower will prevail, by reinforcing resource intake at the optimum efficiency." In this context, the systems thinking and diagramming approach can be seen as a valuable tool to address the challenge of urban planning and management in the name of achieving long-term holistic sustainability.

\section{Case Study}

In order to address a general discourse on sustainable cities and urban metabolism, we propose a study on Metropolitan Area of Naples (Napoli), in Southern Italy. The complexity of urban production and consumption processes is systematically taken into account, including logistic resource supply and recovery chains, transport and storage infrastructures, water and energy management, waste and residues collection, treatment, and recovery. This study aims at designing a circular organization of production and consumption patterns in the metropolitan area at hand, by identifying all the available opportunities (and promoting new ones) for resource saving, as well as for the exchange of still useful resources. This will be achieved by implementing principles of ecodesign, such as waste prevention, resource optimization, and a regenerative and redistributive economy in all aspects of urban organization (production, consumption, households, infrastructures, and services), involving stakeholders, administrators, business units, and organizations. 
The Metropolitan City of Naples is mainly a coastal area located around the Gulf of Naples in the Tyrrhenian Sea, covering a surface of $1,179 \mathrm{~km}^{2}$ and orographically characterized by the presence of short coastal mountain relief, as well as of a volcano, Mount Vesuvius. The Metropolitan City has a resident population of 3,101,000 inhabitants (according to the Italian National Statistics Institute, ISTAT-Istituto Nazionale di Statistica, 2018), with a population density of 2,630 inhabitants $/ \mathrm{km}^{2}$. It is composed of 92 lower administrative bodies, known as Comuni (municipalities), among which Naples represents the chief city. The economy of the city of Naples is mostly focused on the tertiary sector (e.g., local, metropolitan, and regional administrations and governments; healthcare, education, and research; trade and freight transportation, including port activities; and an expanding tourism industry), with limited primary and secondary economic activities. However, the latter are more important in the rest of the Metropolitan Area, which is therefore characterized by a varied economy (ISTAT-Istituto Nazionale di Statistica, 2018). The mobility and logistic infrastructure network of the Metropolitan City of Naples is the most important in Southern Italy (DARA, 2017), with the international airport of Capodichino representing the busiest air station in the macroregion, a railway network composed of slightly more than $1,000 \mathrm{~km}$ of active lines and nine freight-tourist rail systems. Naples is the eighth largest Italian port for freight transport and the first for tourism, the primacy of which is also due to cruise ship activities. At the end of 2018, about 289,500 enterprises were present (i.e., registered and active) in the Metropolitan City of Naples (Camera di Commercio di Napoli, 2018). This work was developed in compliance with the European Union programs and directives for waste reduction, waste recycling, and larger use of renewable resources, as well as EU Directive 2009/28/CE of the European Parliament and of the Council of 23 April 2009 on the promotion of the use of energy from renewable sources (the so-called 20-20-20 Directive), in the framework of Chinese-Italian high-relevance project on urban ecology "MAECI-NSFC," in order to create the basis for a more sustainable urban metabolism in the Metropolitan City of Naples. Although not central to the present work, the study of an urban system as well as possible circular organizations of production and consumption patterns in the Metropolitan City of Naples is proposed as a case study comparable to studies of similar complex systems in China and elsewhere.

MAECI-NSFC ongoing activities include a comprehensive tracking of the key material flows that cities usually depend upon: while also addressing the issue of sustainability through a focus on developing a circular economy (CE), the systems thinking and emergy accounting approaches focus on tracking material and immaterial costs and effects that are usually neglected; thus, the method is potentially able to reinforce the objective to improve sustainability and resilience even outside of the CE mainstream narratives. A "first draft" of the nexus among resources, lifestyles, and urban activities is presented in this work-including the food, energy, and water security nexusand possible collaborative patterns and circular feedbacks are suggested (for the moment) on a qualitative level.
A circular economy (CE), with products designed to ease their recycling, reuse, disassembly, and remanufacturing, is currently expected to replace conventional, "linear" wasteful models used to drive the global economy. Resource constraints, as well as increasing volumes of waste and pollution, threaten urban welfare and well-being, as well as competitiveness, business continuity, profits, and jobs. Therefore, CE policy and technology solutions are proposed to achieve resource conservation and pollutant reduction. In order to deploy the CE framework, and for the general assessment of city sustainability, three main types of matter and energy flows at the urban/metropolitan area level need to be evaluated (Ghisellini et al., 2019):

(i) primary material and energy resources (construction materials, fuels, food, goods, and water), with a focus on waste prevention, minimization of input flows, considering both non-renewable and renewable aspects of the flows and the relative efficacy of each;

(ii) useful flows from one production sector to another (reuse, planning, transferring, exchanging); and

(iii) waste and residues from production and consumption sectors (recycling, recovery, and disposal).

This study addresses an integrated urban systems model that takes maximum advantage of available resources by the optimum use of coproducts, wastes, and residues from all metropolitan sectors via appropriate technologies, networks, and the integration of components, thus saving energy and resources, addressing the problem of waste disposal, and minimizing the environmental impacts of production and consumption. European ecocities best practices (Beatley, 2012; Joss et al., 2013) are found in Germany, Sweden, United Kingdom, and elsewhere. In China, several ecocity projects have been developed (Qiang, 2009; Wong and Yuen, 2011), among which those for Beijing, Shanghai, Tianjin, and Dalian investigate the potential of the $\mathrm{CE}$ for efficient resource use, by decreasing municipal waste production and improving waste treatment, thereby increasing the care for the environment. A preliminary implementation of CE patterns at the lower level of the Municipality of Naples brought about significant reductions in terms of the emergy invested in the system, highlighting that the CE might become a viable alternative business model (Santagata et al., 2020). Nevertheless, strategic long-sighted design and planning are still required to implement an urban $\mathrm{CE}$ that moves toward real sustainability and resilience. In the near future, successful long-term planning is expected to call into question cultural and political aspects of the present system at a higher level of organization, including groundbreaking new values and lifestyle changes, which will occur in addition to innovative technological advances. Therefore, all the primary production and consumption processes in the investigated metropolitan system require us to take into account inequality and other social concerns, as well as the entire base for urban production (agriculture, agroindustrial, commercial, household sectors), while considering that these are occurring in a disadvantaged portion of the country. 


\section{RESULTS}

\section{Systems Diagramming of a City}

As shown it its homonymous section is based on diagramming. Starting from a model originally proposed by Viglia et al. (2018) for some Italian towns and cities, Figure 1 shows a general systemic diagram of a city, more exactly, of a metropolitan area, like the Metropolitan City of Naples. The diagram at hand is basic enough to allow for generalization beyond our case study, and context-specific features can be addressed quantitatively through emergy accounting (Odum, 1996; Brown and Ulgiati, 2016a; Brown et al., 2016; 2016b). In a fully evaluated energy system language (ESL) diagram, the quality and quantity of input flows are described along with the main requirements and operations of the system, as well as desired and undesired products and coproducts (output flows), in this case of the Naples Metropolitan Area.

\section{Key Flows and Sectors in Our Case Study}

Nowadays, many CE policy and technology solutions are proposed to achieve resource conservation and pollutant reduction. As vital components of the city, water, energy, and food, as well as their nexus, are key points for the implementation of CE policies. Various measures, such as the recycling of industrial water, have been taken to ease the heavy burden of water shortage. Besides that, there are circular food policies to address food shortages or food residue issues (e.g., biofermentation, hydrogen production, and anaerobic digestion). The construction of CE scenarios, taking into account not only the water-energy-food nexus but also the purchaseincome-waste generation nexus, may provide different pathways toward the desired CE future.

Therefore, the sustainability of a system calls for appropriate resource use and decreased waste generation. For the Metropolitan Area of Naples, as well as for many other urban systems, this entails dealing with the complexity of various production and consumption processes. The development of computation procedures for circular processes requires a preliminary survey of all urban activities, as well as an agreement on the definition of the methodologies to be applied. Many important circular patterns can be identified in the investigated urban system. To draw attention to the most relevant sectors, a preliminary survey was performed to identify the most representative sectors in the area. Sectors and processes have been chosen based on our knowledge of other metropolitan case studies, either in China, in Italy, or in the rest of the world, for both their regional relevance and their suitability to implement circular patterns. Thus, the selected circular strategies are evaluated, and their implementation proposed for critical processes. The following sectors have been selected for their important role in the economy of the area at issue, as well as to address their potential for the exploration of innovative circular patterns:

- urban tourism industry

- urban waste management

- wastewater treatment
- agri-food chains and residues conversion for value-added products

- WEEE (waste electrical and electronic equipment)

- construction sector

The successful implementation of circular urban systems requires (i) all recovery processes be integrated into the system; (ii) participatory strategies, bottom-up, and top-down interactions, to allow the search for optimized solutions (i.e., optimum compromises) toward prevention of conflicts; (iii) the application of innovative technologies; and (iv) locally creative projects that will supply a roadmap toward well-being through increased environmental care and appropriate resource use and sharing. An important sector that could also be introduced is that of mobility; however, in this sector co-products are difficult to be saved and further exploited, before entering the environment as pollution or waste. This subject deserves a more comprehensive discussion, interrelating many of the selected sectors and implying an even higher level of discussion on values, culture, and politics.

\section{DISCUSSION}

\section{Systems Description of a City}

As shown in the Energy Systems Language model diagram in Figure 1, the operation of a city has general features that can be found in any urban system. The diagram shows that renewable resources, such as solar radiation, wind, and rain, including the geopotential/chemical potential energy of water, and geothermal heat represent the most basic renewable energy drivers of a city, as for any other nature-based system. Coastal cities also draw upon tides and waves, as is the case for the Metropolitan Area of Naples. Local non-renewables are highly variable, depending on the geographic context. However, a common valuable natural resource is represented by soil, whose contribution to system organization is usually expressed as the organic carbon lost in consumed topsoil. Within the physical boundary of a city, environmental production is based on photosynthesis; this produces biomass and (sometimes) a supply of food and other organic materials for the city. The rest of the food and material resources needed are imported from outside the city system. In the diagram, imports are accompanied by services, that is, indirect labor and indirect socioecological costs such as the paid services for extraction or production, manufacturing or processing, and final transportation. Services are exchanged for money, which is expressed by using dashed arrows (money flows) in the diagram. Monetary transactions are represented by diamonds covering resource flows received (solid lines) and money-paid flows (dashed). Among the other imported goods and services are also fuels and electricity. Local inputs and imported inputs contribute to what is defined as the metropolitan economy in the diagram: this encompasses the primary, secondary, and tertiary economic sectors that are required for the functioning of the city, including the feeding and recreation of its human and non-human inhabitants. The city has some exported outputs, which are exchanged on markets for money (right side of the figure) required to buy the inputs from outside. In principle, the systemic goal of 


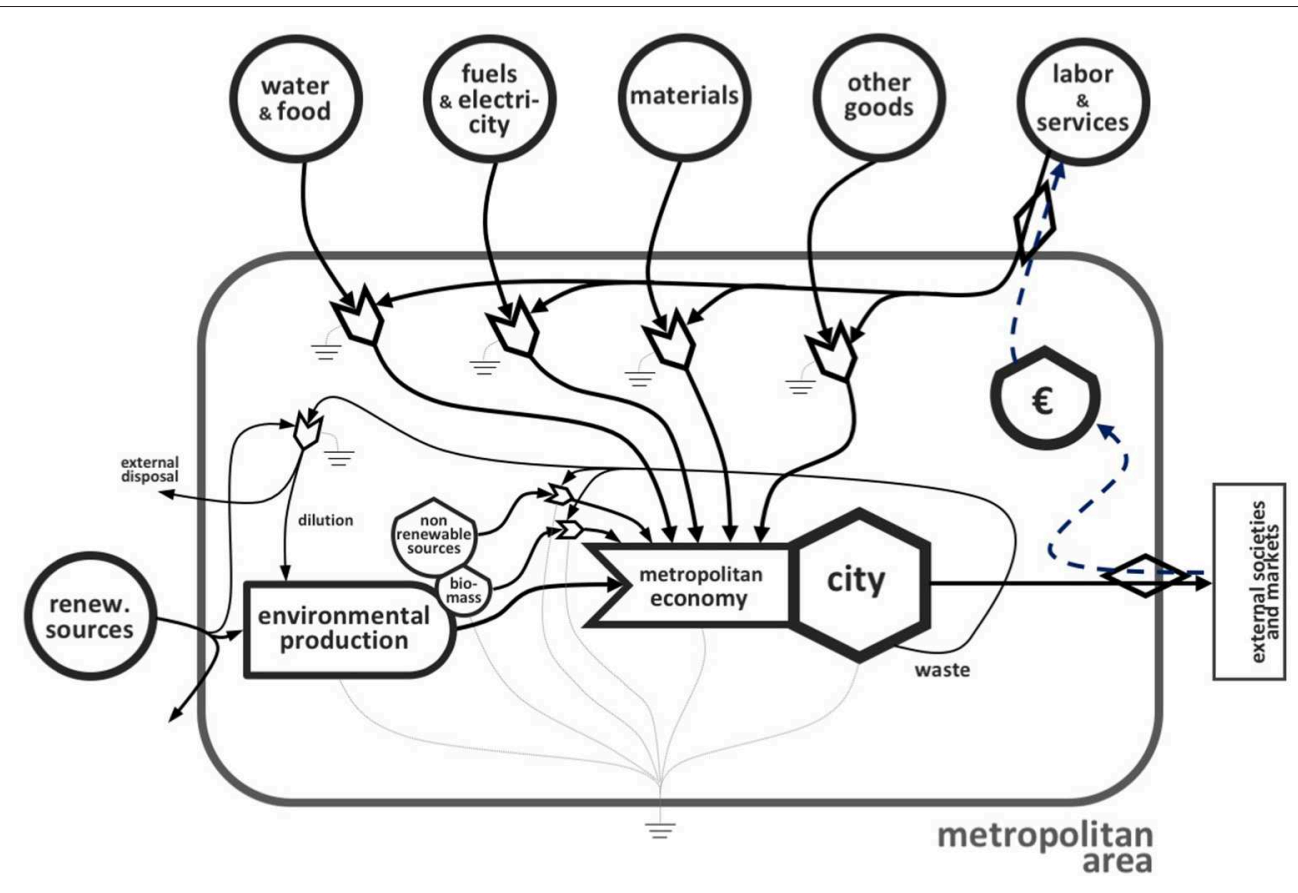

FIGURE 1 | Systems diagram of a metropolitan area.

an urban system is the increased well-being of its population (as generally expressed by hexagonal symbols, which represent users or consumers stocks in the Energy Systems Language, ESL, Odum, 1994). This output directly addresses the concept of sustainability, attained over time within a transgenerational perspective. However, the real factors driving a city are much more complex, including money and profit (for a more extensive treatise on these aspects, see Cristiano, 2018). In addition to the systemic goals of sustainability and resilience, the robustness of metropolitan economic processes also plays an important role. Their speed, which is influenced by the demands of the urban population, and efficiency, which is influenced by the productive and transformative patterns within the city, can determine the pressure on local and imported resources, as well as the waste and pollution generated by the city ${ }^{2}$. Also, such processes can represent what is generally referred to as urban metabolism. It is in this framework that we might interpret the aims and operations of projects and measures seeking circular and collaborative patterns that are genuinely sustainable for urban economies. Premised on these goals, the systems diagram of a city that we have just described, including its stocks and flows, does not represent the outcome of our study, but rather a necessary step for the critical considerations that we illustrate in the following sections. A similar role can be bestowed on our case study, which is used here as an inspiration to describe circular approaches for city development, while

\footnotetext{
${ }^{2}$ As shown in Figure 1, renewables may have an important role, because they dilute and abate the levels of pollution and waste within and out of the urban system. Nevertheless, mass conservation highlights that pollution and waste do remain an issue and should be avoided upstream of their release.
}

proposing theoretical discussions and conclusions that follow from our considerations. Rather than having our case study as the basis for our conclusions, we propose that our concluding thoughts are able to represent an appropriate basis for addressing the case study.

\section{Current Narratives on Urban Planning, Circularity, and Sustainability}

Current narratives on urban planning often claim technological solutions that are able to solve the problems of innovation needed to attain the sustainability of a city. This "technology optimism" (Gonella et al., 2019) is actually rarely justified, most of all because it addresses "local" solutions without taking into account the possible feedbacks connected to the rest of the system, as well as the importance of the support region of the city. This is the case, for example, of the smart interconnectedness advocated by the current Smart City narrative (Gonella, 2019), which should allegedly allow people to directly access city services, thus facilitating the creation of "smart business" entrepreneurship. The same narrative usually does not address any of the changes required in the urban resource inflows, including those of human labor and services. Nor does it address how that part of the citizenry who are excluded from any technological or participatory form of urban life, for example, slum dwellers or the homeless, would gain any profit from e-gov, smart mobility, and interconnectedness of the smart city. Similar considerations may be made for the concept of the $\mathrm{CE}$, applied at the city scale. On the one hand, the $\mathrm{CE}$ is, from all the points of view, clearly an endorsable project. On the other hand, it may have significant relevance in urban policy-making procedures only if it is framed 
in a holistic perspective (Céspedes Restrepo and Morales-Pinzón, 2018), which regards cities as "natural" complex systems obeying the same laws as the rest of nature. This is actually another key point of this article.

\section{General Potentials and Limits of Current Trends and Circular Patterns in Cities}

The proposals to systemically alleviate the upstream and downstream ecological impact of the economic sectors, while reducing waste production, must be built up out of the mainstream narratives. As a matter of fact, there is not yet a full awareness and attention to the current global ecological crisis. Moreover, matching the $\mathrm{CE}$, which is rapidly becoming part of mainstream topics, to the optimization of urban metabolism is expected to allow a change of scale, from a focus on production to a focus on life, as well as from the private to a shared public perspective. The study of this change can be framed within systems thinking and emergy accounting, mixing up hard and social sciences to produce a more lucid and honest analysis than that driven by a purely economic point of view. All the resource flows entering, exiting, and sustaining urban economies are part of a complex self-organizing network of feedbacks, so they must be treated as connected one to another and read from both an upstream and downstream perspective, because a partial reading gives rise to useless partial visions and narratives. Design and planning for more sustainable production and consumption patterns in a metropolitan area can represent a leverage point toward more sustainable urban systems. Preventing the waste of still useful resources is hardly debatable and can be read as one of the largest potential gains for optimizing the urban operations at issue. The problems of city management must be correctly described in terms of waste prevention, ecodesign, resource optimization, and regenerative and redistributive economies, within the various aspects of urban economic processes (e.g., production, consumption, households, infrastructures, services). Furthermore, there should be an effective involvement of stakeholders, administrators, business units, and organizations, all working toward a shared goal of increased well-being, which gets closer to harmonizing the ecological, social, and economic dimensions of sustainability. However, even this might still not be enough. In a century in which great changes are expected to occur and within a context of resource scarcity, we suggest that constant attention is needed to more comprehensively address sustainability issues, verifying the truthfulness of "magic pills" or recipes, which is a crucial regulatory task for science. Systems thinking and diagramming help us to critically read the resource flows of a city. For instance, we address the importance of importing-when pursuing sustainability; specifically, it is necessary to harmonize internal resource optimization and waste reduction with the pressure generated on the urban environment and possibly shifted to city support areas, for example, in terms of external demand for further resources or internal demands for waste processing. Although sharing the reference to general systemic conservation, sustainability, and resilience are different concepts. The definition of sustainability, which is certainly more elusive, has an anthropocentric character, whereas resilience
(Holling, 1973) is a general systemic property. Most of all, sustainability and resilience address different time perspectives. The former indicates what should be the systemic operation now that is able to guarantee the survival and the quality of tomorrow. On the other hand, resilience refers to the capability of reacting now to survive and preserve some systemic quality of now. Of course, several features of a city that can improve its resilience could be equally effective in terms of promoting its sustainability, but the sustainability of a city is strongly interconnected to that of its support systems (regional, national, global). This is one of the main reasons why a proper dynamic systemic analysis is mandatory for any long-term sustainability policy. Jevons (1865) admonished us that energy efficiency is not the same as energy savings: increasing the efficiency in the use of a resource may lead to an increase of its consumption rate, because of the consequential increase of demand and lowering of the price. Therefore, it seems it is finally time to go past current trends, which are recklessly careless of social and ecological issues. However, innovative circular patterns need to acknowledge Jevons' paradox while not neglecting the second law of thermodynamics. From a scientific and systemic viewpoint, we might suggest that applying circular patterns to urban metabolism could be a way to round something off, although not really creating proper circles; that is, improving the sustainability of the systems does not mean that it will make them "ideal."

Speaking of circles, in cycling the spinning speed also matters. Any increase in the cycling speed also increases the rate at which resources are required (hence inserted) into the systemand Jevons' paradox reminds us that increased efficiency causes increases in this spinning speed. Thus, we suggest that decreasing the spinning speed may be one of the goals to help in attaining the sustainability of a given system. In this framework, good candidates for leveraging agents in the system may not be represented by technological advancements, but by forwardlooking ideas. This necessarily calls into question our values, culture, and the overall repoliticization of urban metabolism and urban life in general ${ }^{3}$. One of the major potentials for the redesign of urban metabolism might be a cultural shift from an acceptance of waste as scrap, or discards, to the perspective of waste as a valuable resource to be produced only when necessary and reused until it is no longer possible. Although (or maybe because) culture is thought of as intangible, it is taught and learned and reinterpreted and changed by each new generation, and therefore it emerges as a leverage point to rethink urban metabolic flows now and in the future within a perspective of resilience and sustainability.

\section{CONCLUSION AND PERSPECTIVES}

To improve policies and actions affecting urban sustainability, it is crucial to monitor the resource inflows and outflows, by employing system diagrams that increase our understanding of how they relate to population, resource availability, and environmental carrying capacity (Ulgiati and Zucaro, 2019).

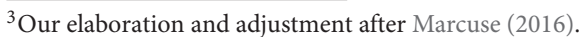


Advocates of business-as-usual growth call for new technological improvements to address new challenges, allegedly relying on the self-regulatory ability of systems. At the same time, degrowth visions and strategies promote a paradigm shift, not only the acknowledgment that unlimited growth is impossible on a limited planet. Game-changing scenarios are usually called for in order to (i) decrease the pressure and demand on the environment, (ii) suggest sustainability and resilience strategies to harmonize internal resource optimization and waste reduction, and (iii) promote patterns for participatory and transparent assessment to move toward greater urban wellbeing. The transition process from linear to circular patterns is already striving-in its more genuine forms-to move toward a cultural change based on a new design to increase reuse and recycling of products. Nevertheless, to ensure an increase in the quality of life and relationships considering different business models, resource availability, environmental protection, and social development requires a path for planning sustainable cities, starting from a rethinking of urban metabolic flows. In order to make sustainability and resilience real in the face of changing, post-growth scenarios, we suggest that systems thinking plays a pivotal role and that the qualitative metabolic analysis of a European metropolitan area can be easily exported to other urban areas of the world. In particular, we conclude that

- applying circular discourses to urban metabolism requires a change of scale in our thinking, from production to life, and of sphere, from private to shared collective goals;

- the use of systems thinking and emergy concepts provides comprehensive transdisciplinary and lucid approaches that will make up for the limits and distortions of using the viewpoints of economists alone;

- soil is a vital resource that cannot be neglected when talking about urbanization;

- cities have large support areas, and we stress the importance of imported resources;

- the size of the flows associated with such imports, as well as control over them, has much to do with urban sustainability and resilience in a changing world;

- although it can be diverted by profit, the theoretical goal of a city is the well-being of its citizens, which requires us to resize flows in order to ensure their lasting availability and our control;

- waste prevention and increased efficiency in the use of urban metabolic resources ought to be matched to an overall rethinking of the speed of internal processes to avoid undesired effects, while keeping in mind both thermodynamic laws and Jevons' paradox;

\section{REFERENCES}

Albino, V., Berardi, U., and Dangelico, R. M. (2015). Smart
Cities: Definitions, dimensions, performance, and initiatives.
J. Urban Technol. 22, 3-21. doi: 10.1080/10630732.2014.
942092

- a holistic perspective is mandatory when addressing urban policy-making procedures in the framework of the $\mathrm{CE}$ concept. Cities must be regarded as "natural" complex systems that obey the same laws as the rest of nature;

- from a systemic point of view, we suggest that acting at the level of design and planning can represent a leverage point for (urban) sustainability; and

- matching this to a paradigm shift able to include and rethink cultural, political, and societal values can be essential to ensure resilience and sustainability in post-growth scenarios.

\section{DATA AVAILABILITY STATEMENT}

The raw data supporting the conclusions of this article will be made available by the authors, without undue reservation, to any qualified researcher.

\section{AUTHOR CONTRIBUTIONS}

Abstract, first draft, introduction, systems diagramming, and conclusion and perspectives mostly by SC. Method mostly by FG. Other resource and discussion mostly by AZ and SC. Details about circular economy evaluation and dynamic modeling mostly by GL. Overall management and editing by SC and AZ. Scientific supervision by SU and FG.

\section{FUNDING}

This work was supported by the Projects of Sino-Italian Cooperation of Natural Science Foundation of China (NSFC, grant No. 71861137001) and the Italian Ministry of Foreign Affairs and International Cooperation, Direzione Generale per la Promozione del Sistema Paese (MAECI, High Relevance Bilateral Projects, grant code PGR05278), Beijing Science and Technology Planning Project (No. Z181100005318001), National Natural Science Foundation (No. 71673029), and the 111 Project (No. B17005). The project is aimed at enhancing urban resource conservation in a CE perspective. The Italian team includes Università degli Studi di Napoli Parthenope (Naples), Università Ca' Foscari Venezia (Venice) as well as Città della Scienza Foundation (Naples), while the Chinese team includes researchers from Beijing Normal University.

\footnotetext{
${ }^{4}$ Such monitoring could possibly use an Urban Circular Economy Calculator (UCEC, Xue et al., 2018), able to envision - through different scenarios sustaining different pathways while considering the food, energy, and water (FEW) nexus. This way, by providing system dynamics for the prediction of system adjustments over time, long-term simulations can accompany more general and theoretical discourses.
} London, UK: Routledge. doi: 10.4324/9781315252049

Araos, M., Berrang-Ford, L., Ford, J. D., Austin, S. E., Biesbroek, R., and Lesnikowski, A. (2016). Climate change adaptation planning in large cities: a systematic global assessment. Environ. Sci. Policy. 66, 375-382. doi: $10.1016 /$ j.envsci.2016.06.009 
Barca, S. (2012a). "Bread and poison. the story of labor environmentalism in Italy, 1968-1998,"in Dangerous Trade. Histories of Industrial Hazards across a Globalizing World. eds Sellers, Christopher; Melling, Joseph (Philadelphia, PA: Temple University Press), 126-139.

Barca, S. (2012b). On working-class environmentalism. a historical and transnational overview. interface. J. Soc. Movements 4, 61-80.

Beatley, T. (2012). Green Cities of Europe: Global Lessons On Green Urbanism. Washington, DC: Island Press. doi: 10.5822/978-1-61091-175-7

Brown, M. T., Campbell, D. E., De Vilbiss, C., and Ulgiati, S. (2016). The geobiosphere emergy baseline: a synthesis. Ecol. Modell. 339, 92-95. doi: 10.1016/j.ecolmodel.2016.03.018

Brown, M. T., and Ulgiati, S. (2016a). Assessing the global environmental sources driving the geobiosphere: a revised emergy baseline. Ecol. Model. 339, 126-132. doi: 10.1016/j.ecolmodel.2016.03.017

Brown, M. T., and Ulgiati, S. (2016b). Emergy assessment of global renewable sources. Ecol. Model. 339, 148-156. doi: 10.1016/j.ecolmodel.2016.03.010

Brulle, R. J., and Pellow, D. N. (2006). Environmental justice: human health and environmental inequalities. Annu. Rev. Public Health 27, 103-124. doi: 10.1146/annurev.publhealth.27.021405.102124

Calvo, G., Valero, A., and Valero, A. (2017). Assessing maximum production peak and resource availability of non-fuel mineral resources: analyzing the influence of extractable global resources. Resour. Conser. Recycl. 125, 208-217. doi: 10.1016/j.resconrec.2017.06.009

Camera di Commercio di Napoli (2018). Localizzazioni $3^{\circ}$ Trimestre 2018. Naples: Camera di Commercio di Napoli.

Campbell, D. E. (2001). Proposal for including what is valuable to ecosystems in environmental assessments. Environ. Sci. Technol. 35, 2867-2873. doi: $10.1021 / \mathrm{es} 001818 \mathrm{n}$

Céspedes Restrepo, J. D., and Morales-Pinzón, T. (2018). Urban metabolism and sustainability: precedents, genesis and research perspectives. Resour. Conserv. Recycl. 131, 216-224. doi: 10.1016/j.resconrec.2017.12.023

Cohen, M. (2017). Systematic review of urban sustainability assessment literature. Sustainability 9:2048. doidoi: 10.3390/su9112048

Cristiano, S. (2018). "Systemic thoughts on ecology, society, and labour," in: Cristiano, S. (Ed.) (2018). Through the Working Class Ecology and Society Investigated Through the Lens of Labour, Venice, Ca' Foscari University Press, Vol. 8, 9-23 (ISBN 978-88-6969-297-0; 978-88-6969-296-3).

Cristiano, S. (2019). Lapproccio Sistemico eMergetico. Prospettive per una Valutazione Integrata Della Sostenibilità Di Progetti Civili e Piani Urbani [The eMergy Systems Approach. Perspectives for an Integrated Assessment of the Sustainability of Civil Works and Urban Plans]. Rassegna Italiana di Valutazione, FrancoAngeli, 71-72/2018, 149-172. doi: 10.3280/RIV2018-071008

Cristiano, S., and Gonella, F. (2019). To build or not to build? Megaprojects, resources, and environment: an emergy synthesis for a systemic evaluation of a major highway expansion. J. Clean. Prod. 223, 772-789. doi: 10.1016/j.jclepro.2019.03.129

D'Alisa, G., Demaria, F., and Kallis, G., (Eds.) (2014). Degrowth: A Vocabulary for a New Era. London, UK: Routledge. doi: 10.4324/9780203796146

DARA (Dipartimento per gli Affari Regionali e le Autonomie, Presidenza del Consiglio dei Ministri) (2017). I Dossier delle Città Metropolitane. Città metropolitana di Napoli, I edizione [ISBN 978-88-99919-02-3].

Demaria, F., Schneider, F., Sekulova, F., and Martinez-Alier, J. (2013). What is degrowth? From an activist slogan to a social movement. Environ. Values 22, 191-215. doi: 10.3197/096327113X13581561725194

Fan, J. L., Kong, L. S., Wang, H., and Zhang, X. (2019). A water-energy nexus review from the perspective of urban metabolism. Ecol. Modell. 392, 128-136. doi: 10.1016/j.ecolmodel.2018.11.019

Forrester, J. W. (1961). Industrial Dynamics. Cambridge, MA: MIT Press.

Ghisellini, P., Santagata, R., Zucaro, A., and Ulgiati, S. (2019). Circular patterns of waste prevention and recovery. E3S Web of Conferences. 119:00003. doi: 10.1051/e3sconf/201911900003

Gonella, F. (2019). The smart narrative of a smart city. Front. Sustain. 9, 1-7. doi: 10.3389/frsc.2019.00009

Gonella, F., Almeida, C. M. V. B., Fiorentino, G., Handayani, K., Span,ò, F., Testoni, R., et al. (2019). Is technology optimism justified? A discussion towards a comprehensive narrative. J. Clean. Prod. 223, 456-465. doidoi: 10.1016/j.jclepro.2019.03.126
Griggs, D., Stafford-Smith, M., Gaffney, O., Rockström, J., Öhman, M. C., Shyamsundar, P., et al. (2013). Policy: sustainable development goals for people and planet. Nature 495, 305. doi: 10.1038/495305a

Hall, C. A. (2004). The continuing importance of maximum power. Ecol. Modell. 178, 107-113. doi: 10.1016/j.ecolmodel.2004.03.003

Hirsch, F. (2005). Social Limits to Growth. London, UK: Routledge.

Holling, C. S. (1973). Resilience and stability of ecological systems. Annu. Rev. Ecol. Syst. 4, 1-23. doi: 10.1146/annurev.es.04.110173.000245

Huang, S., Ye, J., and Chen, L. (2006). A review of urban sustainability indicators: systems framework and policy evaluation. Urban Studies 1, 227-251.

ISTAT-Istituto Nazionale di Statistica (2018). Bilancio demografico nazionale 2018. Available online at: dati.istat.it (accessed October 2018).

Jackson, M. C. (2000). Systems Approaches to Management. New York, NY: Kluwer Academic/Plenum Publisher.

Jevons, W. S. (1865). The Coal Question: An Inquiry Concerning the Progress of the Nation, and the Probable Exhaustion of the Coal-Mines. London, UK: Macmillan.

Joss, S., Cowley, R., and Tomozeiu, D. (2013). Towards the 'ubiquitous eco-city': an analysis of the internationalisation of eco-city policy and practice. Urban Res. Practice 6, 54-74. doi: 10.1080/17535069.2012.762216

Joss, S., Sengers, F., Schraven, D., Caprotti, F., and Dayot, Y. (2019). The smart city as global discourse: storylines and critical junctures across 27 cities. J. Urban Technol. 26, 3-34. doi: 10.1080/10630732.2018.1558387

Lotka, A. J. (1922). Natural selection as a physical principle. Proc. Natl. Acad. Sci. U.S.A. 8:151. doi: 10.1073/pnas.8.6.151

Luna-Reyes, L. F., and Andersen, D. L. (2003). Collecting and analyzing qualitative data for system dynamics: methods and models. Syst. Dynam. Rev. 19, 271-296. doi: $10.1002 /$ sdr. 280

Marcuse, P. (2016). For the repoliticization of global city research. City Commun. 15, 113-117. doi: $10.1111 /$ cico.12177

Martinez-Alier, J., Temper, L., Del Bene, D., and Scheidel, A. (2016). Is there a global environmental justice movement? J. Peasant Stud. 43, 731-755. doi: 10.1080/03066150.2016.1141198

Meadows, D. H. (2008). Thinking in Systems: A Primer. White River Junction, VT: Chelsea Green Publishing.

Meadows, D. H., Meadows, D. L., Randers, J., and Behrens, W. W. (1972). The limits to Growth. New York, NY.

Monat, J. P., and Gannon, T. F. (2015). What is systems thinking? A review of selected literature plus recommendations. Am. J. Syst. Sci. 4, 11-26. doi: $10.5923 /$ j.ajss.20150401.02

Odum, H. T. (1983). Systems Ecology: An Introduction. New York, NY: John Wiley.

Odum, H. T. (1988). Self-organization, transformity, and information. Science 242, 1132-1139. doidoi: 10.1126/science.242.4882.1132

Odum, H. T. (1994). Ecological and General Systems: An Introduction to Systems Ecology. Niwot, CO: University Press of Colorado.

Odum, H. T. (1996). Environmental Accounting: Emergy and Environmental Decision Making. New York, NY: John Wiley and Sons.

Olsen, E. S., Orefice, M., and Pietrangeli, G. (2018). "From the 'right to the city' to the "right to metabolismm," in Housing for Degrowth: Principles, Models, Challenges and Opportunities. eds A. Nelson, and F. Schneider (London, UK: Routledge), 33-44. doi: 10.4324/9781315151205-3

Orr, D. (2014). Systems Thinking and the future of cities. Solutions. Available online at: http://www.thesolutionsjournal.com/node/237149

Pulido, L., and De Lara, J. (2018). Reimagining 'justice' in environmental justice: radical ecologies, decolonial thought, and the black radical tradition. Environ. Plann. 1, 76-98. doi: 10.1177/2514848618770363

Qiang, M. (2009). "Eco-city and eco-planning in China: taking an example for Caofeidian eco-city," in Proceedings of the 4th International Conference of the International Forum on Urbanism (Delft), 511-520.

Ripple, W. J., Wolf, C., Newsome, T. M., Barnard, P., and Moomaw, W. R. (2019). World scientists' warning of a climate emergency. BioScience. 70, 8-12. doi: 10.1093/biosci/biz088

Rivas, M. I., and Nonhebel, S. (2016). Assessing changes in availability of land and water for food (1960-2050) An analysis linking food demand and available resources. Outlook Agric. 45, 124-131. doi: 10.1177/0030727016650767

Sachs, J. D. (2012). From millennium development goals to sustainable development goals. Lancet 379, 2206-2211. doi: 10.1016/S01406736(12)60685-0 
Santagata, R., Zucaro, A., Viglia, S., Ripa, M., Tian, X., and Ulgiati, S. (2020). Assessing the sustainability of urban eco-systems through Emergy-based circular economy indicators. Ecol. Indic. 109, 1-10. doi: 10.1016/j.ecolind.2019.105859

Sterman, J. D. (1994). Learning in and about complex systems. Syst. Dynam. Rev. 10, 291-330. doi: 10.1002/sdr.4260100214

Sterman, J. D. (2012). "Sustaining Sustainability: creating a systems science in a fragmented academy and polarized world," in Sustainability Science: The Emerging Paradigm and the Urban Environment, eds M. P. Weinstein, and R. E. Turner (New York, NY: Springer), 21-58. doi: 10.1007/978-1-4614-3188-6_2

Ulgiati, S., and Zucaro, A. (2019). Challenges in urban metabolism: sustainability and well-being in cities. Front. Sustain. 1, 1-3. doi: 10.3389/frsc.2019.00001

United Nations (2015). Transforming our World: The 2030 Agenda for Sustainable Development.

United Nations (2019). UN Climate Action Summit 2019. Available online at: https://www.un.org/en/climatechange/un-climate-summit-2019.shtml

United Nations Department of Economic and Social Affairs (2018). 2018 Revision of World Urbanization Prospects. Available online at: https://population.un.org/ wup/

United Nations Department of Economic and Social Affairs (2019). World Population Prospects 2019. Available online at: https://population.un.org/wpp/

Viglia, S., Civitillo, D. F., Cacciapuoti, G., and Ulgiati, S. (2018). Indicators of environmental loading and sustainability of urban systems. an emergy-based environmental footprint. Ecol. Indic. 94, 82-99. doi: 10.1016/j.ecolind.2017.03.060 von Bertalanffy, L. (1968). General System Theory: Foundations, Development, Applications. New York, NY: George Braziller.

Wong, T. C., and Yuen, B. (2011). Eco-City Planning. Policies, Practice and Design. Dordrecht: Springer Science+ Business Media BV. doi: 10.1007/978-94-007-0383-4

Xue, J., Liu, G., Casazza, M., and Ulgiati, S. (2018). Development of an urban FEW nexus online analyzer to support urban circular economy strategy planning. Energy 164, 475-495. doi: 10.1016/j.energy.2018. 08.198

Zhao, Y., and Wang, S. (2015). The relationship between urbanization, economic growth and energy consumption in China: an econometric perspective analysis. Sustainability 7, 5609-5627. doi: 10.3390/ su7055609

Conflict of Interest: The authors declare that the research was conducted in the absence of any commercial or financial relationships that could be construed as a potential conflict of interest.

Copyright (C) 2020 Cristiano, Zucaro, Liu, Ulgiati and Gonella. This is an open-access article distributed under the terms of the Creative Commons Attribution License (CC $B Y)$. The use, distribution or reproduction in other forums is permitted, provided the original author(s) and the copyright owner(s) are credited and that the original publication in this journal is cited, in accordance with accepted academic practice. No use, distribution or reproduction is permitted which does not comply with these terms. 